\title{
hMENA splicing program impacts the clinical outcome of early stage lung cancer patients. How and why?
}

\author{
Paolo Visca' ${ }^{1}$, Sheila Spada ${ }^{1}$, Francesca Di Modugno ${ }^{1}$, Emilio Bria ${ }^{2}$, Isabella Sperduti ${ }^{1}$, Barbara Antoniani ${ }^{1}$, \\ Gabriele Alessandrini ${ }^{1}$, Belinda Palermo ${ }^{1}$, Vienna Ludovini ${ }^{3}$, Lucio Crinò ${ }^{3}$, Francesco Facciolo ${ }^{1}$, Michele Milella', \\ Marcella Mottolese ${ }^{1}$, Paola Nisticò ${ }^{1 *}$
}

From Melanoma Bridge meeting 2013

Naples, Italy. 5-8 December 2013

\section{Background}

In lung cancer, reliable prognostic indicators of the risk of recurrence are still not available. Alternative splicing represents a potential biomarker of diagnosis, prognosis, invasiveness, and response to therapy in different tumors [1], including lung cancer [2].

Human MENA (hMENA) is an actin regulatory protein that modulates cell adhesion and migration [3]. We have isolated three hMENA splice variants, namely hMENA, hMENA $^{11 \mathrm{a}}$ and hMENA $\Delta \mathrm{v} 6$, impacting differently cell shape and function. hMENA ${ }^{11 a}$ expression ensures the integrity of cell-cell adhesion and is associated with an epithelial phenotype, whereas hMENA $\Delta \mathrm{v} 6$ is related to a mesenchymal invasive phenotype. The splicing of hMENA, relevant to epithelial mesenchymal transition, is also regulated by microenvironmental cues [4].

The dynamic reciprocity between tumor and stroma influences the tumor tissue architecture including the $\mathrm{T}$ cell localization. This, proposed as a prognostic marker [5], is a prerequisite for antitumor immune surveillance and recently the antibody blockade of immune checkpoints is a new reality in lung cancer treatment $[6,7]$.

\section{Materials and methods}

Pan-hMENA and specific hMENA ${ }^{11 a}$ Abs were tested by immunohistochemistry on duplicate TMA from 248 N0 NSCLC, and clinical factors (sex, age, histology, grading, $\mathrm{T}$-size, number of resected nodes, $\mathrm{RN}$ ) were correlated to 3-yr disease-free (DFS), cancer-specific (CSS), and overall

\footnotetext{
* Correspondence: nistico@ifo.it

${ }^{1}$ Regina Elena National Cancer Institute, Rome, Italy

Full list of author information is available at the end of the article survival (OS) using a Cox model. ROC analysis provided optimal cut-off values and model validation. A logistic equation including regression analysis coefficients was constructed to estimate individual patients' probability (IPP) of relapse. Internal cross-validation (100 simulations with $80 \%$ of the dataset) and external validation was accomplished.

A panel of antibodies recognizing CD3, CD4, CD8, CD20 molecules has been employed for the characterization and localization of lymphocytes, by immunohistochemistry.

\section{Results}

In the series of NO NSCLC patients (median follow-up: 36 months, range 1-96), Pan-hMENA and hMENA ${ }^{11 a}$ were the only biological variables displaying significant correlation with outcome(s), confirmed by the crossvalidation (replication rate: $78 \%, 83 \%$ ), with a prognostic model accuracy of $61 \%$ (standard error $0.04, \mathrm{p}=0.0001$ ). The subgroup of patients with High Pan-hMENA/Low hMENA $^{11 a}$ relative expression fared significantly better than the other 3 groups ( $\leq \leq 0.002$ for all outcomes). On the basis of the combination between this molecular hybrid variable and T-size and RN, a 3-risk class stratification model was generated, discriminating between patients at different risk of relapse, cancer-related death, and death for any cause, with a prognostic accuracy of $61 \%$ (standard error $0.03, \mathrm{p}=0.01$ ), according to ROC analysis and validated in an independent dataset of 133 patients.

The correlation between hMENA isoforms and the pattern of expression and localization of lymphocytes in the different groups of risk of relapse identified is under evaluation. 


\section{Conclusions}

The hMENA splicing program is an early prognostic marker of NSCLC patients and may represent a surrogate marker of a permissive or not tumor microenvironment for lymphocyte recruitment.

\section{Authors' details}

${ }^{1}$ Regina Elena National Cancer Institute, Rome, Italy. ${ }^{2}$ Medical Oncology, Azienda Ospedaliera Universitaria Integrata, University of Verona, Verona, Italy. ${ }^{3}$ Medical Oncology, S. Maria della Misericordia Hospital, Perugia, Italy.

Published: 6 May 2014

\section{References}

1. Pal S, Gupta R, Davuluri RV: Alternative transcription and alternative splicing in cancer. Pharmacol Ther 2012, 136(3):283-94.

2. Stallings-Mann ML, Waldmann J, Zhang Y, Miller E, Gauthier ML, Visscher DW, Downey GP, Radisky ES, Fields AP, Radisky DC: Matrix metalloproteinase induction of Rac1b, a key effector of lung cancer progression. Sci Transl Med 2012, 4(142):142ra95.

3. Di Modugno F, Bronzi G, Scanlan MJ, Del Bello D, Cascioli S, Venturo I, Botti C, Nicotra MR, Mottolese M, Natali PG, Santoni A, Jager E, Nisticò P: Human Mena protein, a serex-defined antigen overexpressed in breast cancer eliciting both humoral and CD8+ T-cell immune response. Int J Cancer 2004, 109(6):909-18.

4. Di Modugno F, lapicca P, Boudreau A, Mottolese M, Terrenato I, Perracchio L, Carstens RP, Santoni A, Bissell MJ, Nisticò P: Splicing program of human MENA produces a previously undescribed isoform associated with invasive, mesenchymal-like breast tumors. Proc Natl Acad Sci U S A 2012, 109(47):19280-5.

5. Fridman WH, Pagès F, Sautès-Fridman C, Galon J: The immune contexture in human tumours: impact on clinical outcome. Nat Rev Cancer 2012, 12(4):298-306.

6. Pardoll DM: The blockade of immune checkpoints in cancer immunotherapy. Nat Rev Cancer 2012, 12(4):252-64.

7. Brahmer JR, Tykodi SS, Chow LQ, Hwu WJ, Topalian SL, Hwu P, Drake CG, Camacho LH, Kauh J, Odunsi K, Pitot HC, Hamid O, Bhatia S, Martins R, Eaton K, Chen S, Salay TM, Alaparthy S, Grosso JF, Korman AJ, Parker SM, Agrawal S, Goldberg SM, Pardoll DM, Gupta A, Wigginton JM: Safety and activity of anti-PD-L1 antibody in patients with advanced cancer. $N$ Engl J Med 2012, 366(26):2455-65.

doi:10.1186/1479-5876-12-S1-P12

Cite this article as: Visca et al:: hMENA splicing program impacts the clinical outcome of early stage lung cancer patients. How and why? Journal of Translational Medicine 2014 12(Suppl 1):P12.

\section{Submit your next manuscript to BioMed Central and take full advantage of:}

- Convenient online submission

- Thorough peer review

- No space constraints or color figure charges

- Immediate publication on acceptance

- Inclusion in PubMed, CAS, Scopus and Google Scholar

- Research which is freely available for redistribution

Submit your manuscript at www.biomedcentral.com/submit
C Biomed Central 